\title{
中國早期鋼鐵治煉技術上 創造性的成就”
}

\author{
周 志 宏
}

(交通大祭)

\section{一而 青}

近椟紀來，世界鋼鐵冶煉技街，隨着重工業 的發展, 突飛猛進。而中國在解放前却停滞不 前, 追和過去中國反動梳治對鋼鐵工業的摧殘分 不開的。但中國在銅鐵冶䐈技術方面的成就最 早, 而且極其出色，這是世界學者所公認的。

中國早期鋼鐵冶煉技術最突出的表現在蘇錩 （相傳篇江蘇某氏所弡明）的冶煉的方 法上, 追 是一種創造性的成就。當址珮方法没有發明以 前，世界鋼鐵冶煉技術還停留於低混冶整即所謂 熟鐵的階段，由於温度未能提高，鋼液不流動， 産生了鐵與渣涬不能分離的問題。無數的先進工 作者都篇此作了不少的努力。經過長時間的固體 碳,一種較强較硬的鋼是可以獲得了, 但共中 仍有殘渣存在, 問題没有全部解决。中國在问一 階段中也有類似的過程, 如內地出産的毛鐵（土 墪熟鐵）、矿銅（雲南白花樹）、士鋼等都屬於同 一的範疇, 是中國古代勞動人民在遶方面的成

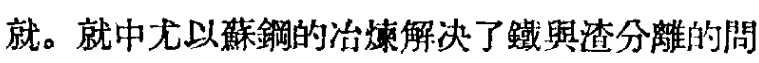
題。它的冶煉方法是利用料鐵（即未經鉦撃的毛 驖) 中的渣和淋入的生鐵, 使之發生氧化作用, 結果查滓被除掉, 保留了適合需要性能的鋏。

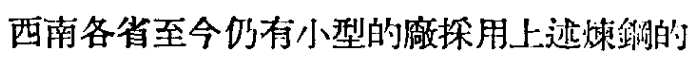
方法. 作者在抗戰時, 會作了比較哚入的洞查研 究。作者認第在中國早期鋼鐵冶煉技術上宣是一 程創造性的成就, 值得我們珍視。這篇報告係以 重度北倍附近金岡挽的一個廠第例來做說朋。

解放至今, 短短的五年中, 新中國在鋼鐵以 及其冶煉技㯈方面收檴很多, 如產量的情復、質
量的提高、新銓種的試煉以及大規模的新建與拉 建, 充分說明了這一方面的重大弡展。面對着日 益壯大的鋼鐵工業, 作者認篇: 對中国早期鋼鐵 冶煉技術上的成就作比較有系流的阎逝, 是有其 價浒的。這篇報告並希望能有助於將來編鼠中國 銅鐵史的寥考。

\section{二 設确與赫作}

作者数重庋北碚金㣚碑附近的一個煉鈰廠進 行調查的時間是在 1938 年。散處四川一丵逜一 類小型煉金闒廠的設備與操作情况大致相似。造個 煉銅廠的經常工作, 多係在午後至午夜的時間內 進行。

契煉設借方面十分简單。主要的雼三個部

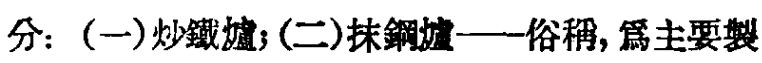

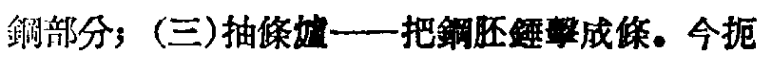
要說明如下:

\section{(一)炒鐵媪}

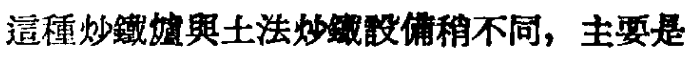
爐底後部有曥橋（曥橋面皘 $7.6 \times 19.1$ 厘米 ${ }^{2}$ ), 由 橫列的嘘佟六根組成, 其間留有約 0.3 厘米的空 陁，篇通風之用。炒鐵曥膛近似打鐵㠊，成立體 長方形 (高14厘米)，左右後壁係用耐火砂石 图 成，頂部和前面開敛，以便操作。

炒鐵的操作:

進行炒鐵㭙, 先把木炭擊碎, 舖入摖內至全 容量的一半，再將放在爐上預熱的敘板 (長在7.6 厘米以下, 重䄪 4.25 公厅) 加入㜋內, 上䤄再覆一

- 本文係作者於 1954 年 10一-11 月在中國科學院 塞行的金磁研工作報告會上所作報告的摘要。 


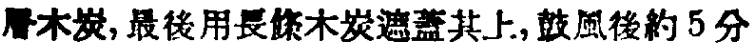

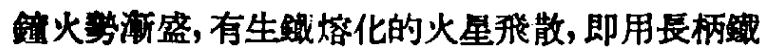

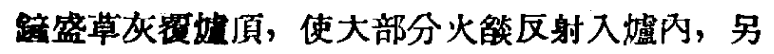
一部分的火篍自㠊後上部逸出, 將放置㠊頂附近 的制板預熱至較高温度。大部熱量道時已集中於 嫬內, 温度迅速增高, 站在㠊前的炒手, 以左手

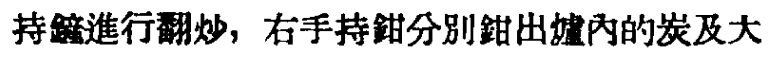

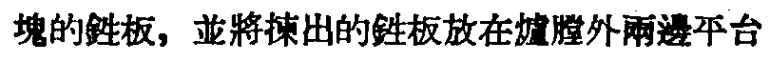
上。分别地由鉏手及鼓風手將其打碎, 然後用 草把將細碎的鐵塊重還㠊內, 同時將紅炭渣檢 出, 值至嘘內的炭完全檢畫, 鉎板完全鉷碎篇

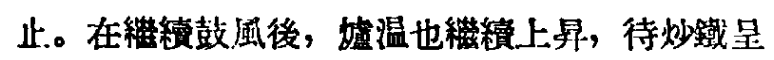

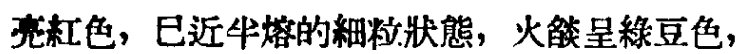

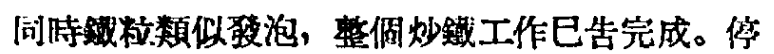

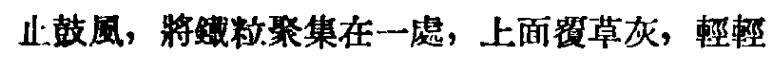
打平, 四周也放監草灰, 淮行拍聚, 然後夾江放 入草灰中，使縓綏冷却。移時再鋁出，在鐵磪上 用手鋽聚成長方形後, 用宰刀切成三佟, 重約 2.5 至 3 公斤, 道就是料鐵, 成爲次一步驟中的 炴鋼原料。全部過程約 15-17 分鐘。

\section{(二)抹鋼像}

它是煉銅過程中的主要部分（圖 1 甲、乙、 丙)。嫬高 0.7 米左右。㠊前部煉銅部分係由砂石

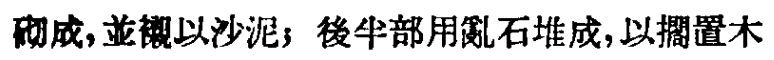
炭與料鐵，燥銅部分的結構形似撲滿（舊俗儲銅

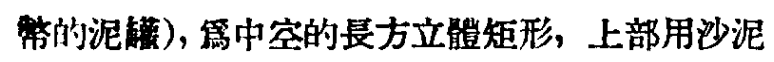
揘成的藍板掩復, 蓋板前部有正方形的開口。底 部爲㹨長方形, 坡底部分由四根熱鐵條構成, 本

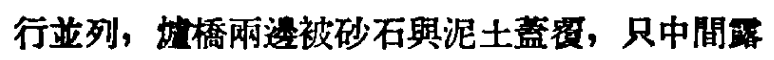
出三孔,䙾約2.5厘米, 由於枯鋼次數較多, 孔阻塞

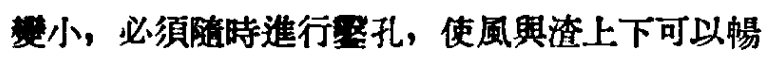
通, 以保證槵鈴的作用進行無阻。鼓風設備, 比 交特殊, 雨储風箱本列用砂石别成, 截面成三觕 形,箱內以筧 40.6 厘米、高 96.5 厘米的薄木板二塊

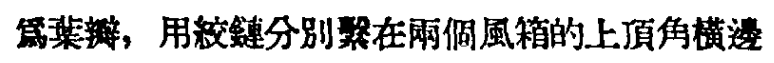
上, 木板的下部有方孔, 內裤厚布, 爱空氣的進 口, 再下有鐵環連接於長柄的一端, 㯰储長柄就 是工人操作的把手（圖 1 甲、乙). 往返抽動時, 風被連嫔地鼓入。㯰種結權的方法, 可使櫖中獲 得足够的風压和風量。同時並提高了昽內的温度。 抹金的操作:

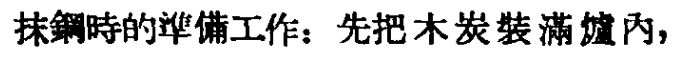

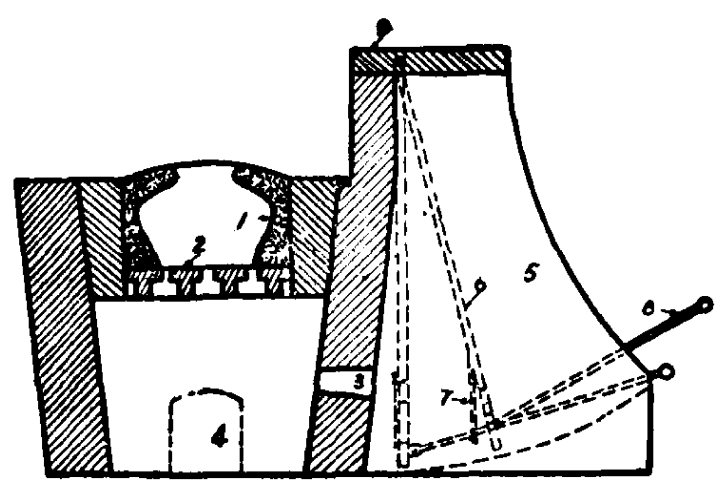

甲

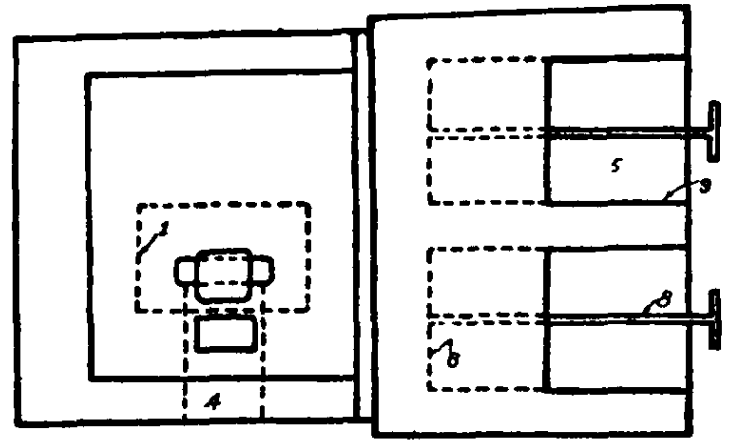

乙

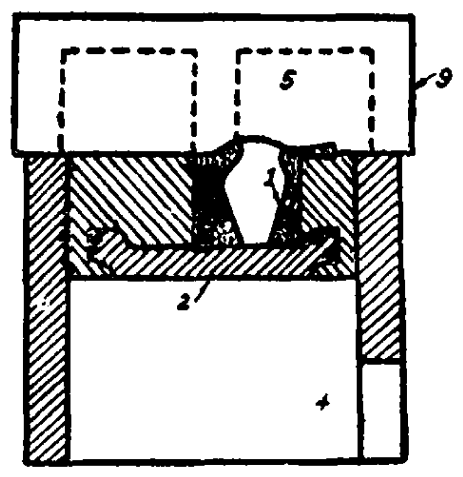

网

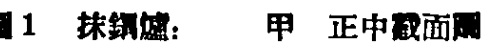

乙本面圆

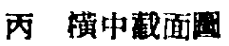

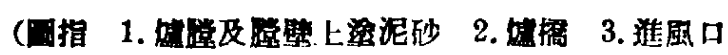

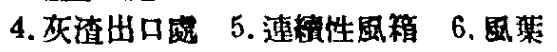

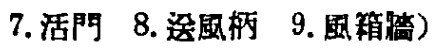

在嘘外焢口的旁透，置料鐵兩條，加蕰，鼓風，

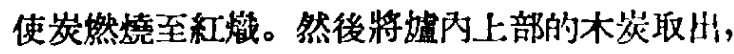

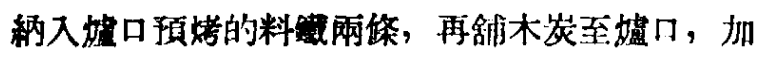
上㠊蓝，㠊口四周堆放木炭，這時用力鼓風，經

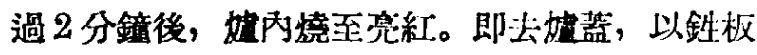
兩塊(每塊直約0.75公厅, 成長方形)，一塊置㠊外 


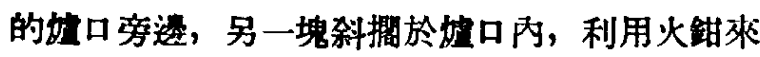
支持它, 繼續用力鼓風, 嘘內温度已逐漸升高達 $1,000^{\circ} \mathrm{C}$ 左右, 3 分鐘後, 栎擱在熆口內的那塊 鉎板的一端開始揢化，從㠊口喷出的火能中爽有 鐵板的火花，此時温度約在 $1,300^{\circ} \mathrm{C}$ 在右。抹鋼 工人在造時開始至嫬前操作：以左手握大鉬夾任 鐵板，左右移動，使熔化下滴的鐵珠均匀地滴於 料鐵上，產生劇烈的锌化作用; 同時以右手執鋼 勾不斷翻動料鐵，使料鐵各部分能均匀地畫量吸 收鐵液。這是極其重要的一步工作，除需要熟綀 的技巧外，更要求能看料錢的火色來决定滴抹鐵 液的步璪。大部分的抹鋼工人都能以辦别姷內的 火色來决定鼓風快慢的程度。經過 6 分鐘後，第

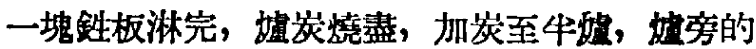
另一塊鉎板被提至爐口下，仍鹤以火鈤支持，加 蓋鼓風，4 分鐘後，鉎板開始熔化，進行第二次 的淋鐵，至鉎板塔完䨋止。於是停止鼓風，夾出

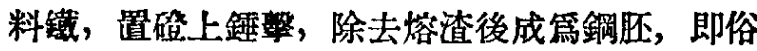
稱篇鋼團。整侗操作時間約窟 25-35 分鐘。

\section{(三)抽條加:}

它的構造簡單，與普通的紅妮相似。 抽條的操作:

抽條的工作大致與打鐡的工作相同，就是把

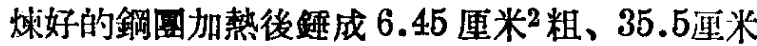
長的鎆條，在銅料台呈紅色時投入冾水中淬冷之。

全部操作過程中（自炒銭至抽條）鉎板消耗 頗大，超過牛數以上。

\section{三梌瞼}

(一)成分的检驗

1. 原料:

炒鐵的原料一一践板（即土熆生座的生鐵成 板狀）是四川募陵江沿岸的土法崃鐵㠊的產物， 含矽低，而含磷、硫也不高。

成分如下:

C 3.05\% Si 0.28\% Mn 0.18\%（㑑则鉎 板中亦有含銀較高的） S $0.05 \%$ P $0.22 \%$

2. 料鐵:

含碳遠較毛絞高。組織疏散，含查多。 成分如下:

C $0.92 \%$ (個别料践中亦有碳在共析以下的)
Si $0.19 \% \quad M n \quad 0.10 \% \quad S \quad 0.02 \% \quad P \quad 0.08 \%$

3. 鋼様:

甲、鋼團的成分:

碳高。在工人的總驗控制下，恰到好處，道 合於工具鋼的成分，硫、磷、斜都很低。

C $0.91 \% \quad$ Si $028 \% \quad \mathrm{Mn} 0.01 \%$

S $0.01 \% \quad P \quad 0.05 \%$

乙、鋼條的成分:

中段外部 C $0.92 \%$ Si 0.036\%

Mn $0.024 \% \quad$ S $0.008 \% \quad \mathrm{P} 0.037 \%$

中段內部 C $0.92 \%$ Si $0.034 \%$

Mn $0.029 \% \quad$ S $0.011 \% \quad$ P $0.046 \%$

鋼條內部與外部成分相㳊很微，成分向屬均

匀, 在牛流體狀態慗煉過程中是比較奞得的。

鋼團中矽的成分存在狀態難於断定，但在鋼 焂中含㱛很低，於此也可以答明：鐝中含渣亦很 少。除银矽成分低外，其他成分完全合乎碳素工 具䟜的成分。

從原料到成品的分析, 可以看出: 銅料中不 僅含渣少，經過炒践與淋鐵的過程，磷、硫也有 顯著的降低，因此增進了鋼的品質。

(二)金相檢驗（附硬度檢驗）

1. 料鐵:

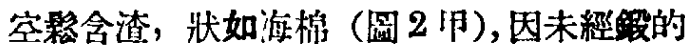
過程，含渣較多，不及二鐵的細密。主要的組成

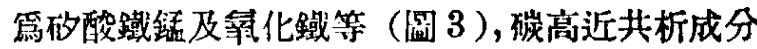
（圆 4)，佰别部分碳低，因在牛流動狀熊生成， 各部成分稍不一致是可能的。

2. 鋼團:

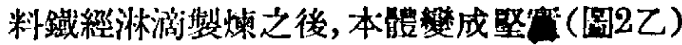

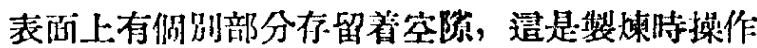
上仢缺點，淋滴的作用未完圣，縫䧄部分含渣並 有脫碳現像，鋼團含碳高，舀過共析銅的粗料 (圆 5 )。

3. 鍓條:

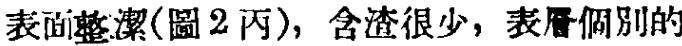
部分有時含渣, 有時渣存晶粈周圍, 晶界末完全塔 合，是由鋼團未淋滴完全遗留下来的缺陷。社火

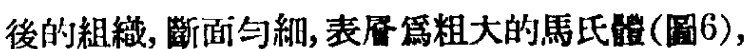
表首以內開始有届E體疏落地存在昆界上(时7), 亦有較粗的届氏鳢和馬氏體出現（回 8 ），湖别 


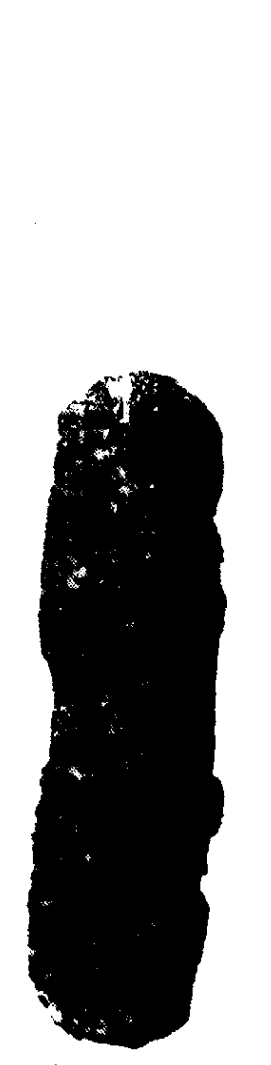

甲

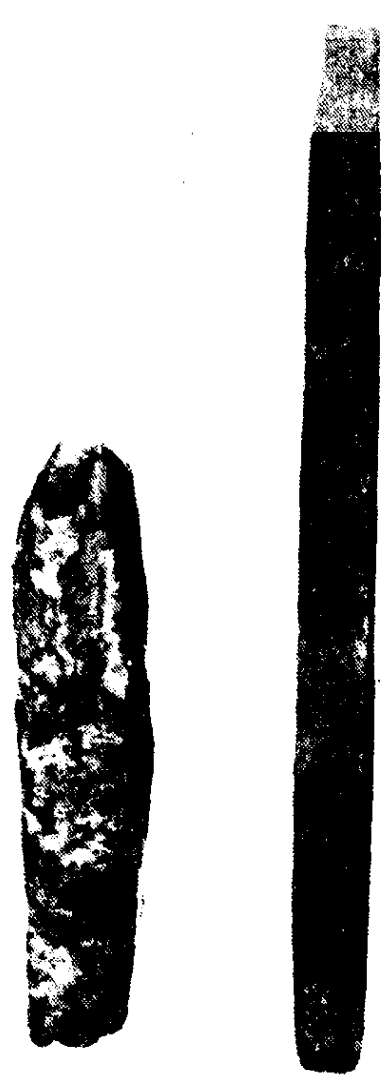

两

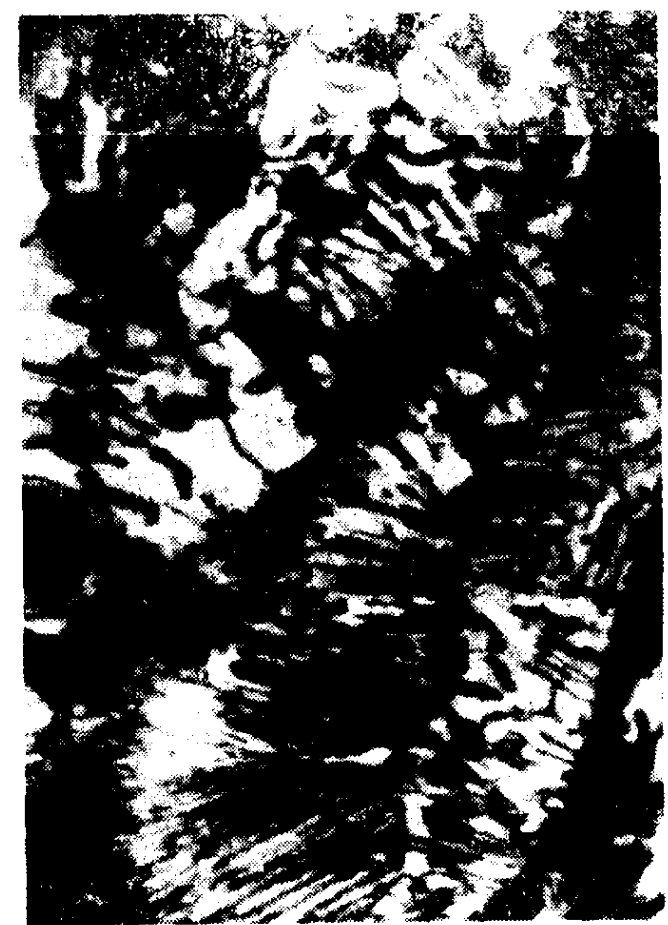

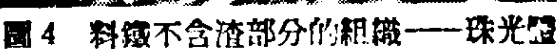
$4 \%$ 硣酸液浸蝕

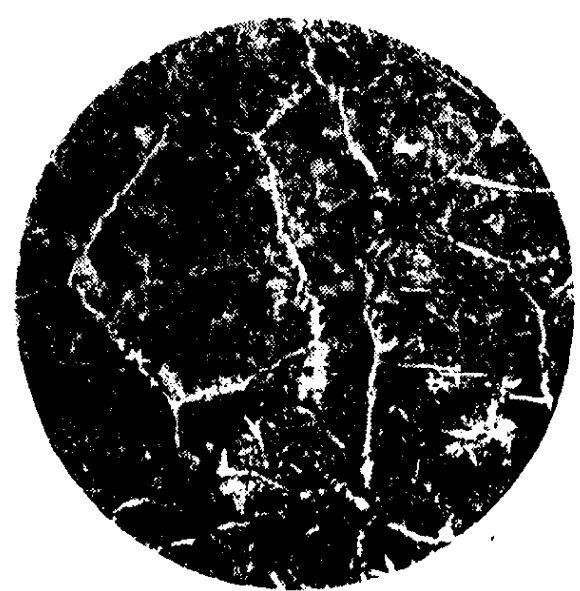

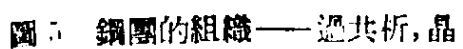

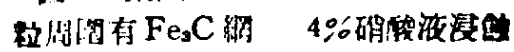

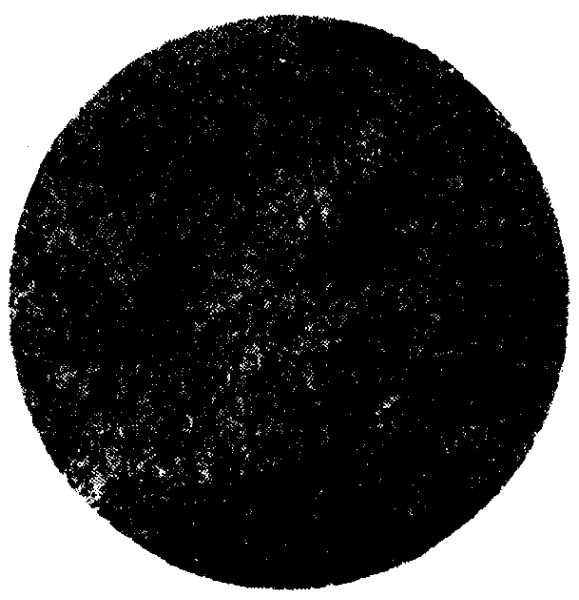

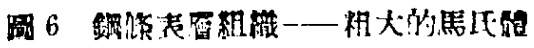
$4 \%$ 硐酸液漫䖵

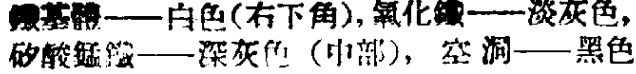
(它上解) 
的部分在有届氏䯏的晶界上有 $\mathrm{Fe}_{8} \mathrm{C}$ 的析出 （凅 9）, 有的截面中粗織不甚均匀可能因冾却的 情况不同，或表面成分性能调别部分有些差别。

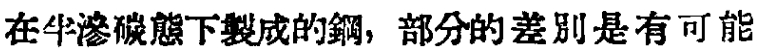
的.

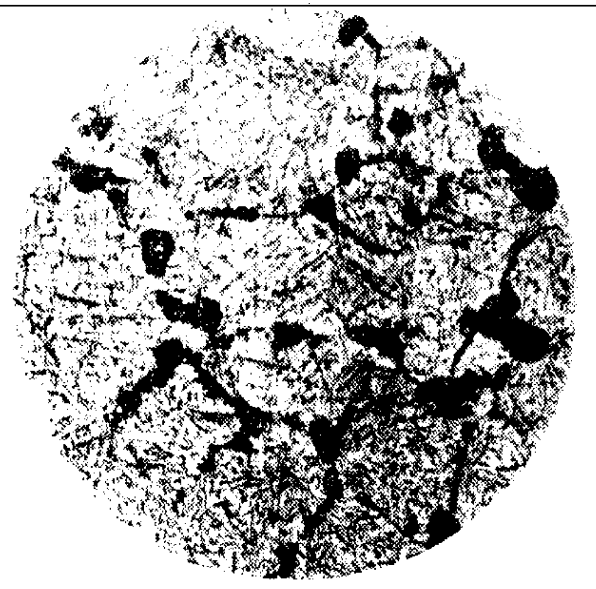

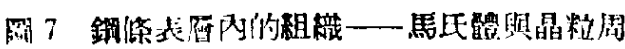

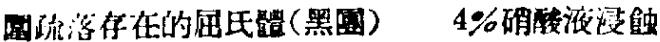

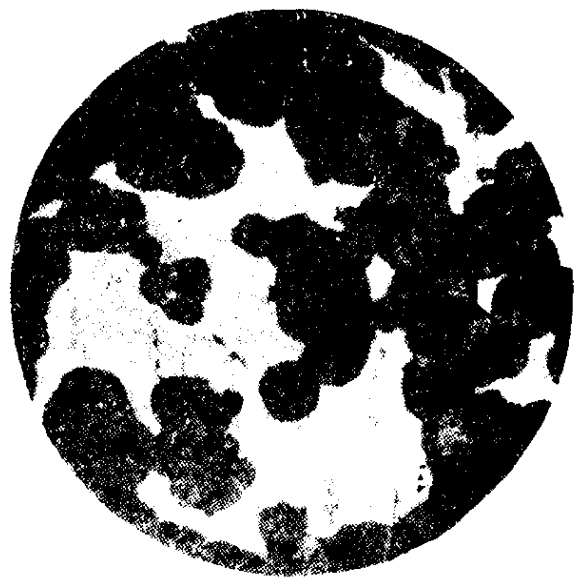

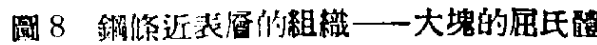

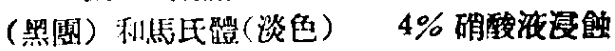

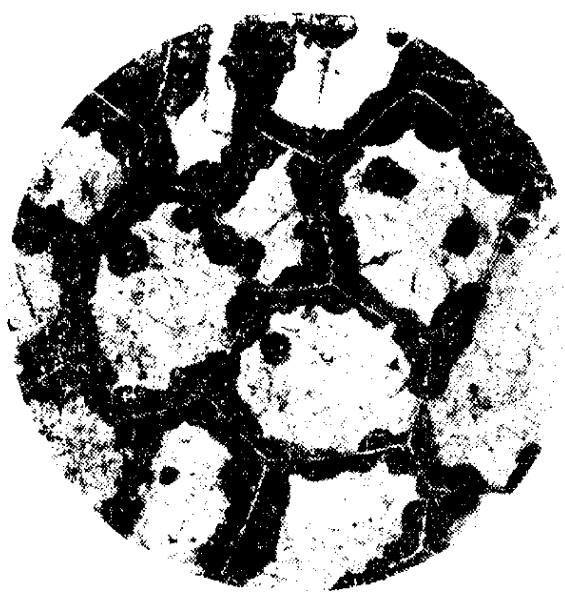

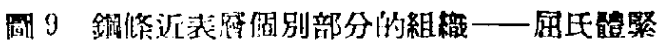

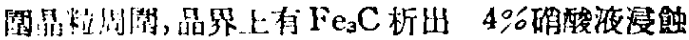

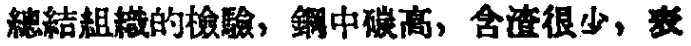
面可以淬硬成盆馬氏體。

4. 硬度检驗:

係用末淬火的龬佟，沿鋼佟上分五段。（每 點距離約 7-8 喜米, 用洛氏硬度計測定如下;

$\begin{array}{llllll}5 & 4 & 8 & 2 & 1\end{array}$

Rc 28-. $\quad-42 \quad \bullet-33 \quad-44 \quad-435 \quad \cdots 35$ $\cdot-32 \cdot-32 \cdot-40 \quad-40 \quad \cdot-34$

個別部分硬度相差較大。影示牛塔體狀態下 煉成的鋼，在未淋滴完善的部分有硬度的美是 可能的。

\section{四中， 政}

依摭作者的望地考察和取棦检驗的桔果，可 以肯定地說：逼種煉銅方法是和世界工策先進国 家早期的煉銅方法不同，它們過去所有的器 碳銅等方法，我們都有，可是上面所說的呠龬方 法, 在國外塄没有類似的破現, 顯然是一種刢造 性的墢明! 必須指出: 䄐種方法設備很簡陑，材料 單純，原料消耗很大，但整個的操作過程却能適合

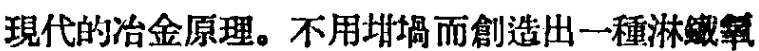
化的方法使渣鐵分開，成篇比較純的工。具鋼，逼是 中國古代先進煉鋼工作者的智慧結晶。他們利用 生鐵的高碳和低熔點，可以在低温時塔化，成滴 地滴入料鐵，同時也由於料鐵䟽繁，易於吸收鐵 液，並使其分散成圌無數小珠流入料鐵內各倜䗋 简中，與存留其中的㨀化渣緊密地磼生作用，並讯 速地除去新啠，減低碳分，趛特渣鐵分開，渣浮 於表面，逐潮流出體外，而驖湤中碳份降低到相當 程度, 即不再流動, 而留於海棉䌡內, 直至全部空

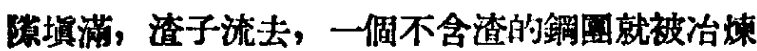
成功了。通種利用料鐵的結構桃分散渣和鐵液至 顺細小的個登，以涬到增加接触面和氧化速度的 方法與近代白林快速煉鐝法在原则上是没有什 區别的。依據對成品的檢查，缺點是有的：如硬 度上有點寥美，鋼糨的表面還有空陆，個别部分

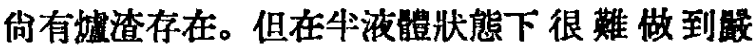
格的控制, 所以還是含渣少, 成分較匀的座物。 通蔓值得我們注意的是在成分方面: 除银、矽㘬 低外，其他都興碳素工具鋼的成分完全相似。至 於硫、特低的原因，係由於原料的磁，硫已在 
炒料時去共一部分，在抹銈時又去其一部分，故 含量特低。在低温度時, 在含多量莒化践迫的作 用下，逜是可以做到的，但渣雜的去除，碳份的適 合興均与, 完全体賴於液體鐵珠的大小和降落的 頻数的控制, 以及對温度的調節。在通方面熟練 工人的蜗作, 也是值得稱道的。他們恣自己的豐

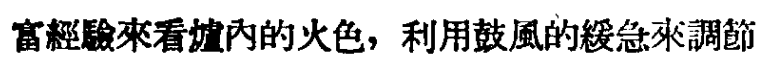
温度和作用的快慢, 在當時没有新式科樂的測温 設借, 單恣經驗來控制, 不能不說是一種傑作。 從座品所顯示的細小顆粒.及均匀的淬硬斷䤄, 與 近代工具銚悲乎完全相似, 所以中國早期鋼鐵冶 煉的技徆是符合科學的原理的。過去西南各省由 於交通不方便，鋼材不易輸入，遭種鋼料健筬刃 具、具慗造所必需, 探了相的作用。

\section{五結 的}

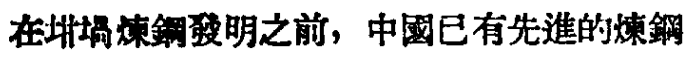
工作者作出了巨大的成就。新他們的創造至今遗

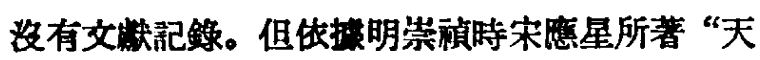
工開物” 書內的記载: “凡幟分生帮, 出植未炒则
生, 既炒則熟, 生熟相和, 煤成则鍓。……銅

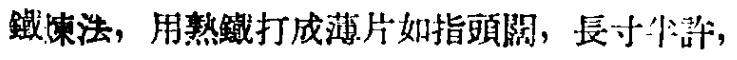
以践片束包尖（夾）緊, 生鐵安置其上, ……洪

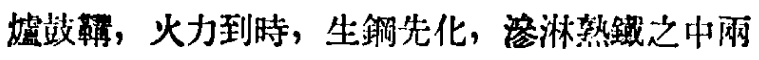
情投合, 取出加踇, 再煉再銡, 不一而足, 俗名 團䞒，亦日萑鋼者是也。”

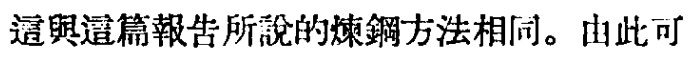

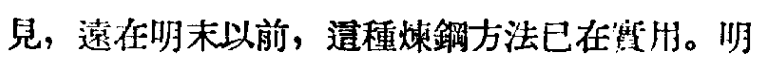

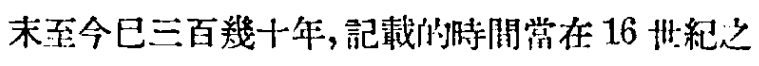
末與 17 世紀的初期。他們是在学時没有影微鏡 設備, 没有臨界温度的依據, 並且又與世界治梀

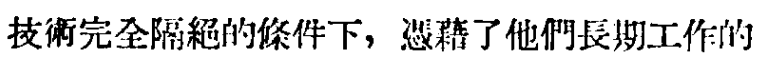

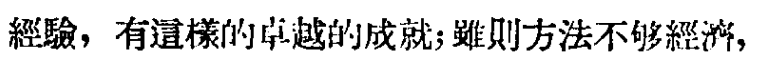
座显低, 品質也不能完全一致, 但他們所刢造的

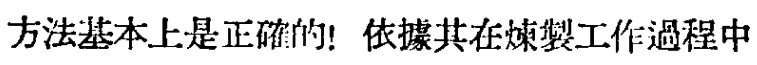
脗合近代的冶金原理一點桃推諭, 這些先進工作 者在當時是有一定的理論基礎的。

我們早期這些不知名的先進工作者是我們民 族的傑出人物。對他們在早期刢造性的成就是不 能不給予很高的誨平價的!

\section{〔上接 41 具〕}

種工作提出了新的任䅂，如。果北小麥越冬性問 題, 北部棉花的早熱性和抗素箱性問題, 作物 復壯工作中如何㙁進親本間的差異性問題, 架篗 選種時親本的選擇和定向培育的原則和具能方法 問題，熱带植物的北移問題，以及品種的抗性、 不倒伏等經济性狀和有谷的適應力閣題等等, 都 涉及遗傅等的理諭問題。通些問題的解决將大大

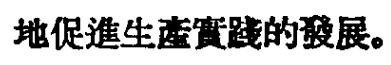

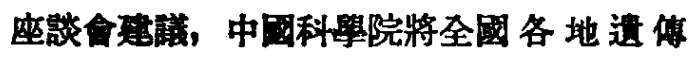

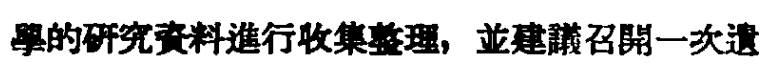

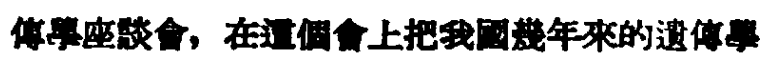

研究工作加以總結, 並提出今後的任移和方向。 此外，座影會建議國內有關的科學刊物多介紹磪 聯遺傅學研究的成果和原則。

從座談會的報告和討論的研究題目中可以看 到在各地區科學研究中發育生理的咑究, 一方面门

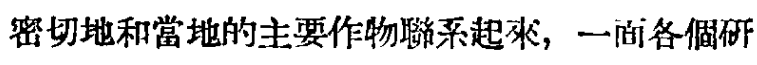

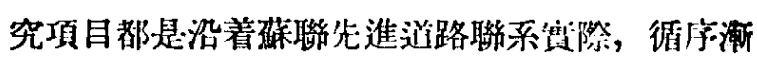
淮地墢展着, 因之箁我國弡育生理的進一步研究 打下了基碟。

\section{（黄季芳管紹弶）}

